\title{
Study of Four Element Microstrip Antenna Array Using Patch Type Electromagnetic Band Gap Structure
}

\author{
K. Prahlada Rao \\ Department Of PG Studies and Research \\ in Applied Electronics \\ Gulbarga University \\ Gulbarga, India
}

\author{
P. V. Hunagund \\ Department Of PG Studies and Research \\ in Applied Electronics \\ Gulbarga University \\ Gulbarga, India
}

\author{
R. M. Vani \\ University Science Instrumentation \\ Centre \\ Gulbarga University \\ Gulbarga, India
}

\begin{abstract}
This paper describes an enhancement in the performance of four element microstrip antenna array. The conventional microstrip antenna array is producing gain equal to $6.81 \mathrm{~dB}$. With the introduction of $U$ shape patch type electromagnetic band gap structure, the proposed microstrip antenna array is producing an improved gain of $20.33 \mathrm{~dB}$. It is producing reduced mutual coupling of $-31.44,-36.41$ and $31.62 \mathrm{~dB}$ respectively. The radiation characteristics of the proposed microstrip antenna array are improved with appreciable decrease in back lobe radiation and increase in forward power. It is resonating at single band at $5.53 \mathrm{GHz}$, producing an overall bandwidth of $109.45 \%$, against $4.89 \%$ of conventional microstrip antenna array. Microstrip antenna arrays are designed using Mentor Graphics IE3D software and measured results are obtained using vector network analyzer.
\end{abstract}

Keywords-corporate feeding; gain; microstrip antenna array; mutual coupling; resonant frequency

\section{INTRODUCTION}

Antennas play an important role in proper working and development of various communication systems. Immense research towards the development of novel, sophisticated and efficient types of antennas is on the rise. Microstrip antennas are made of radiating patch or conductor and ground plane placed on either side of substrate. Microstrip antennas can be basically seen as sudden discontinuities which represent changes in their geometry and shape. These discontinuities are responsible for changes in the current, electric and magnetic field distributions. The most important inherent characteristics and serious limitations of microstrip antennas and arrays are narrow bandwidth and high mutual coupling values. The thickness of the radiating patch plays a crucial part when conductor losses are being calculated [1-7]. Applications involving microstrip antennas and arrays have driven research towards enhanced antenna bandwidth. Bandwidth of microstrip antennas and arrays can be enhanced by various methods like stacking, metamaterials, decreasing relative permittivity of the dielectric and defective ground structures. Nowadays, electromagnetic band gap (EBG) structures are being employed on a large scale to improve the efficiency of microstrip antennas. These structures consist of periodically placed unit cells. One of the notable features of EBG structures is that the dimensions of the unit cell are lesser than that of the radiating patch [8-16].

\section{CONVENTIONAL MICROSTRIP ANTENNA ARRAY}

Conventional microstrip antenna array (CMAA) designed at $6 \mathrm{GHz}$ consists of four identical rectangular radiating patches. The substrate employed to design the antenna arrays is FR-4 glass epoxy which has a dielectric constant of 4.2 and loss tangent of 0.0245 . The height of the substrate is $1.6 \mathrm{~mm}$. Each of the radiating patches has dimensions of $15.73 \mathrm{~mm} \times 11.76 \mathrm{~mm}$. The quarter wave transformer has dimensions of $6.47 \mathrm{~mm} \times 0.47 \mathrm{~mm}$. The feeding element has dimensions of $6.52 \mathrm{~mm} \times 3.05 \mathrm{~mm}$. CMAA is fed by corporate feeding technique. The distance between the adjacent radiating elements of CMAA is $\lambda / 4$, where $\lambda$ is the wavelength calculated at the design frequency of $6 \mathrm{GHz}$. The schematic of CMAA is shown in Figure 1 and its dimensions are shown in Table I.

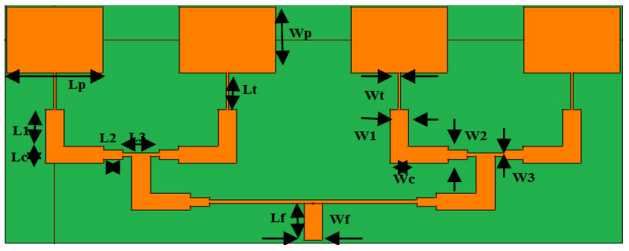

Fig. 1. Schematic of CMAA.

The four radiating patches of CMAA are arranged in such a way that the distance between the adjacent radiating patches is the same with that of Figure 1. This setup is arranged to measure mutual coupling between the radiating elements. Moreover, the elements of CMAA are excited independently with the same amount of power. The S-parameters $S_{21}, S_{31}$ and $\mathrm{S}_{41}$ designate the mutual coupling coefficients. In the $\mathrm{S}$ parameters the first digit designates the output port and the second digit designates the input port. Figure 2 depicts the schematic of arrangement of elements of CMAA to measure the mutual coupling. 
TABLE I. CMAA PARAMETER VALUES

\begin{tabular}{|c|c|}
\hline Parameter & Value(mm) \\
\hline Length of the patch (Lp) & 15.73 \\
\hline Width of the patch (Wp) & 11.76 \\
\hline Length of the quarter wave transformer (Lt) & 6.47 \\
\hline Width of the quarter wave transformer (Wt) & 0.47 \\
\hline Length of the $50 \Omega$ line (L1) & 6.52 \\
\hline Width of the $50 \Omega$ line (W1) & 3.05 \\
\hline Length of the coupler & 3.05 \\
\hline Width of the coupler & 3.05 \\
\hline Length of the $70 \Omega$ line (L2) & 6.54 \\
\hline Width of the $70 \Omega$ line (W2) & 1.62 \\
\hline Length of the $100 \Omega$ line (L3) & 6.56 \\
\hline Width of the $100 \Omega$ line (W3) & 0.70 \\
\hline Length of the feed line (Lf) & 6.52 \\
\hline Width of the feed line (Wf) & 3.05 \\
\hline
\end{tabular}

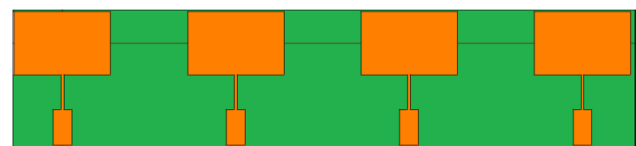

Fig. 2. Schematic of arrangement of elements of CMAA to measure mutual coupling.

\section{DESIGN OF PROPOSED MICROSTRIP ANTENNA ARRAY}

The unit cell of the EBG structure is depicted in Figure 3. The unit cell of the EBG structure employed consists of a Ushape patch type. The dimensions of the unit cell are $\mathrm{P}=5 \mathrm{~mm}$ and $\mathrm{Q}=4 \mathrm{~mm}$ respectively. The EBG structure employed to enhance the performance of CMAA is depicted in Figure 4.

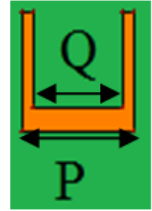

Fig. 3. Schematic of unit cell of EBG structure.

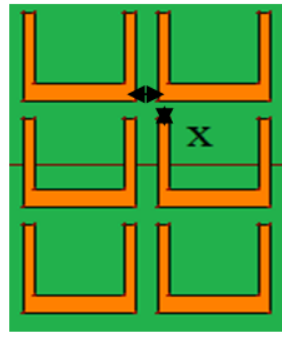

Fig. 4. Schematic of EBG structure.

It consists of a matrix of 2 columns and 3 rows of U-shape patch type unit cells. The unit cells of the EBG structure are repeated after every $1 \mathrm{~mm}$ along the $\mathrm{x}$-axis and y-axis. The periodicity is represented by $\mathrm{X}$. The proposed microstrip antenna array (PMAA) is designed by loading the EBG structure shown in Figure 4 on the surface and in between the radiating patches of CMAA. The schematic of PMAA is shown in Figure 5. In order to measure the change in the values of mutual coupling coefficients after the introduction of U-shape patch type EBG structure, the EBG structure depicted in Figure 4 is kept on the surface of the schematic shown in Figure 2.
The schematic employed to determine the mutual coupling in the presence of U-shape EBG structure is depicted in Figure 6.

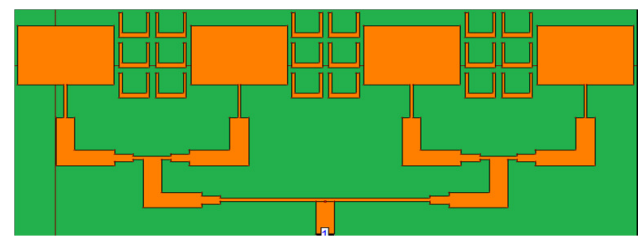

Fig. 5. Schematic of PMAA.

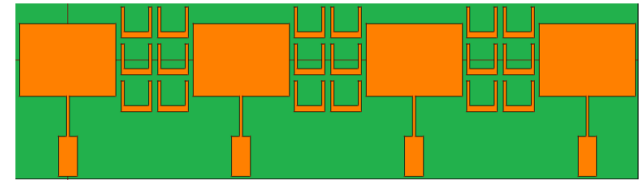

Fig. 6. Schematic of arrangement of elements of PMAA for the measurement of mutual coupling.

\section{FABRICATED MICROSTRIP ANTENNA ARRAYS}

Figures 7-10 show photographs of the fabricated antenna arrays.
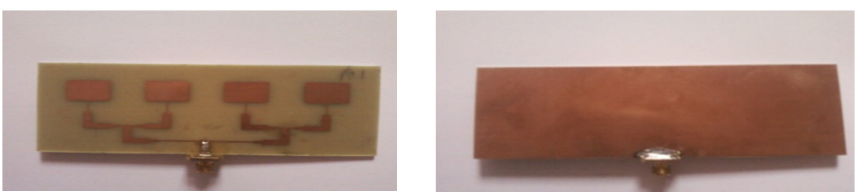

Fig. 7. Photograph of CMAA.
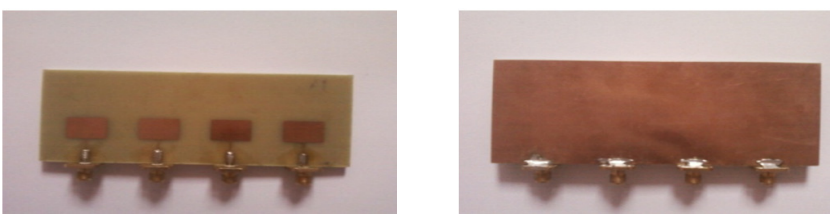

Fig. 8. Photograph of CMAA elements arrangement for mutual coupling measurement.

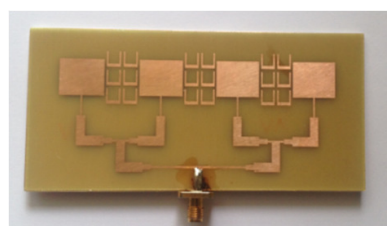

(a)

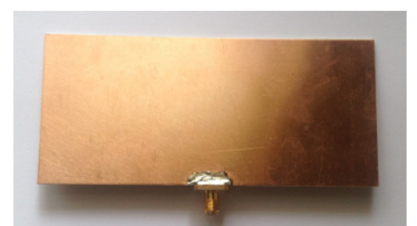

(b)
Fig. 9. Photograph of PMAA, (a) Front view, (b) back view.

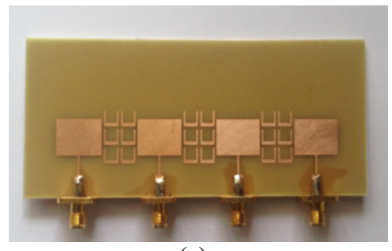

(a)

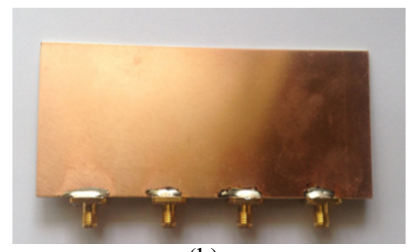

(b)
Fig. 10. Photograph of PMAA elements arrangement for mutual coupling measurement. (a) Front view, (b) back view. 


\section{MEASURED RESULTS}

The performances of CMAA and PMAA are judged in terms of bandwidth, return loss, resonant frequency, mutual coupling, gain, forward power, back lobe radiation, front to back ratio (FBR) and virtual size reduction. Figures 11, 12 and 13 depict the graphs of return loss and mutual coupling versus frequency of CMAA.

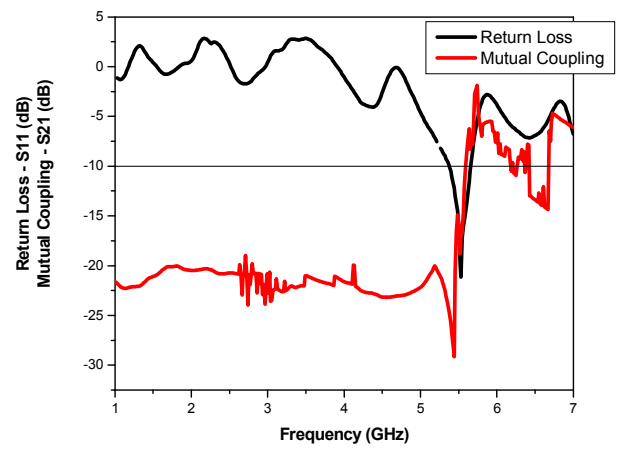

Fig. 11. Graph of return loss and mutual coupling- $\mathrm{S}_{21}$ versus CMAA frequency.

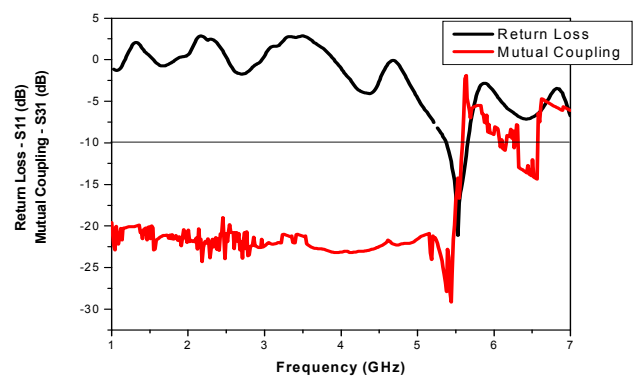

Fig. 12. Graph of return loss and mutual coupling-S $\mathrm{S}_{31}$ versus CMAA frequency.

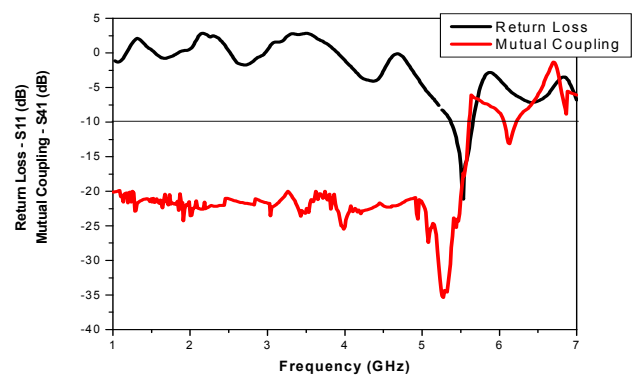

Fig. 13. Graph of return loss and mutual coupling- $\mathrm{S}_{41}$ versus CMAA frequency.

Figures 11,12 and 13 indicate that CMAA is resonating at $5.53 \mathrm{GHz}$ and producing a return loss of $-21.06 \mathrm{~dB}$. The mutual coupling values measured at the resonant frequency of $5.53 \mathrm{GHz}$ of CMAA are equal to $\mathrm{S}_{21}=-16.95 \mathrm{~dB}, \mathrm{~S}_{31}=-14.22 \mathrm{~dB}$ and $\mathrm{S}_{41}=-17.30 \mathrm{~dB}$ respectively. These values of mutual coupling plots are considered to be very high and need to be decreased. Another result that can be extracted from Figures 11-13 is that the graphs of return loss and mutual coupling are overlapping. This implies there is an interference level between the transmitting antenna 1 and the receiving antennas 2-4. Parameter bandwidth can be determined from the return loss graph in Figures 11-13. Bandwidth is calculated by subtracting the lower frequency from the upper frequency where the return loss is crossing the $-10 \mathrm{~dB}$ value. Hence the bandwidth of CMAA is equal to $273 \mathrm{MHz}$. Bandwidth can be expressed in terms of percentage as:

$$
\text { Bandwidth }(\%)=\frac{\text { Bandwidth }}{\text { Resonant Frequency }} \times 100
$$

Hence substituting the relevant parameters in (1), the bandwidth (\%) of CMAA is equal to $4.89 \%$. Figures 14,15 and 16 depict the graphs of return loss and mutual coupling versus frequency of PMAA. Figures 14-16 depict that PMAA is resonating at the same fundamental frequency with CMAA i.e. at $5.53 \mathrm{GHz}$. Additionally, PMAA is resonating at single frequency. The total bandwidth produced by PMAA is very high and equal to $6.05 \mathrm{GHz}$. In terms of bandwidth (\%), it is equal to $109.45 \%$. Therefore, in terms of bandwidth (\%) PMAA is a better candidate than CMAA, because PMAA is producing enhanced bandwidth (\%) compared to CMAA, which is producing narrow bandwidth of $4.89 \%$.

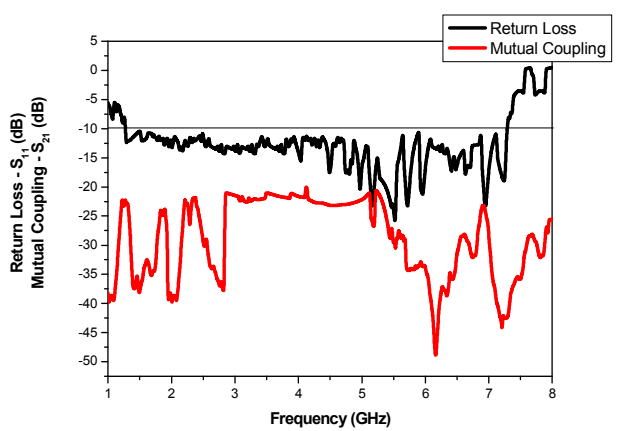

Fig. 14. Plot of return loss and mutual coupling- $\mathrm{S}_{21}$ versus PMAA frequency

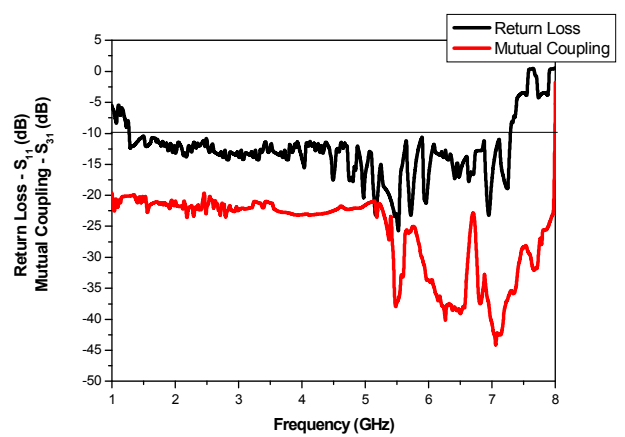

Fig. 15. Plot of return loss and mutual coupling-S $\mathrm{S}_{31}$ versus PMAA frequency.

Information about the mutual coupling coefficients of PMAA are obtained from Figures 14, 15 and 16. At resonant 
frequency of $5.53 \mathrm{GHz}$, the mutual coupling values of PMAA are equal to $\mathrm{S}_{21}=-31.44 \mathrm{~dB}, \mathrm{~S}_{31}=-36.41 \mathrm{~dB}$ and $\mathrm{S}_{41}=-31.62 \mathrm{~dB}$ respectively. Thus in the presence of U-shape patch type EBG structure, the values of mutual coupling coefficients are decreased. Moreover, the plots of mutual coupling and return loss are no more crossing each other at the resonant frequency of $5.53 \mathrm{~Hz}$. This implies that the amount of interference between the antenna element 1 and the antenna elements 2, 3 and 4 is considerably reduced. Reduction of mutual coupling confirms that PMAA is performing better than CMAA in terms of mutual coupling.

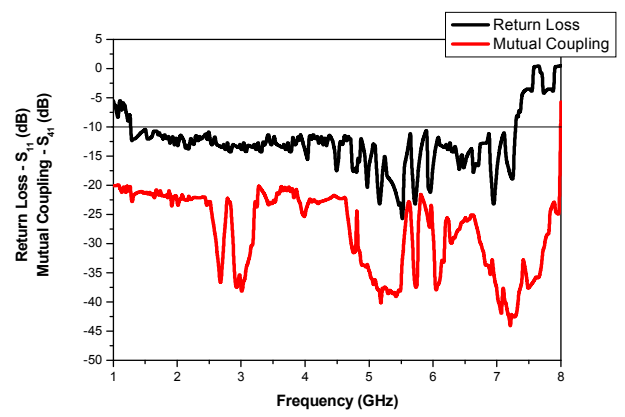

Fig. 16. Plot of return loss and mutual coupling- $\mathrm{S}_{41}$ versus PMAA frequency.

The parameter Gain is calculated by (2):

$$
G=20 \log _{10}\left(\frac{4 \pi R}{\lambda}\right)+10 \log _{10} \frac{P r}{P t}-G t
$$

where $P t$ is the transmitted power, $P r$ is the received power, $R$ is the distance between the transmitting and the receiving antennas, $\lambda$ is the wavelength at the resonant frequency of $5.53 \mathrm{GHz}$, and $G t$ is the gain of the transmitting antenna, given by (3):

$$
\begin{aligned}
& G t=10 \log _{10} G s \\
& G s=\frac{2 \pi a b}{\lambda^{2}}
\end{aligned}
$$

where $\alpha$ and $b$ are the length and width of the standard pyramidal horn antenna used as the transmitting antenna. Dimensions $\alpha$ and $b$ are equal to $24 \mathrm{~cm}$ and $14 \mathrm{~cm}$ respectively. The distance between the transmitting antenna (standard horn antenna) and the receiving antenna is given by (5):

$$
R \geq \frac{2 D^{2}}{\lambda}
$$

where $\mathrm{D}$ is the larger dimension of the transmitting antenna equal to $24 \mathrm{~cm}$. The value of $\mathrm{R}=71.86 \mathrm{~m}$.

The transmitted and received powers in the case of CMAA are equal to $8.7 \mu \mathrm{W}$ and $12.414 \mathrm{nW}$ respectively. Substituting these values in (1), the gain of CMAA becomes equal to $6.81 \mathrm{~dB}$. In the case of PMAA, the transmitted and received powers are equal to $8.7 \mu \mathrm{W}$ and $0.279 \mu \mathrm{W}$. Substituting into (1), the gain of PMAA is $20.33 \mathrm{~dB}$. Hence with the introduction of U-shape patch type EBG structure, the gain of PMAA is increased, hence PMAA is a better antenna compared to CMAA regarding gain. Figure 17 shows the radiation plot of CMAA and PMAA.

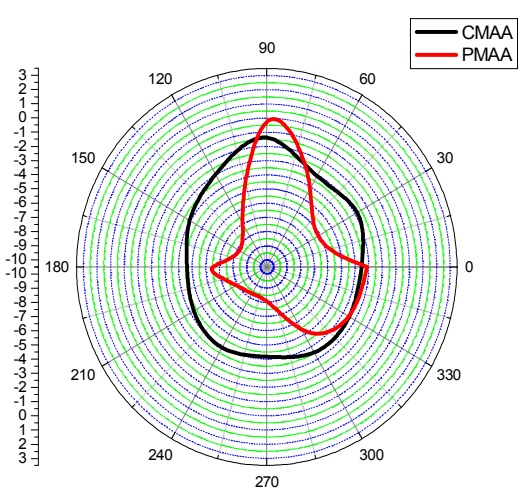

Fig. 17. Radiation plot of CMAA and PMAA.

Using the radiation pattern, the amount of forward and backward power radiated is determined. To sketch the radiation pattern, the standard pyramidal horn antenna is employed as transmitting antenna and CMAA and PMAA as receiving antennas. The radiation pattern is plotted for angle from $0^{0}$ to $360^{\circ}$ in a polar plot. The forward power radiated is measured at $90^{\circ}$ and the backward power at $270^{\circ}$. Initially considering CMAA, the forward and backward powers measured are equal to -2 and $-4.5 \mathrm{~dB}$ respectively. The corresponding powers radiated by PMAA are -0.5 and $-8 \mathrm{~dB}$ respectively. We see that PMAA is radiating increased power in the forward direction and lesser power in the backward direction compared to CMAA. Hence PMAA is a better radiator than CMAA in terms of forward and backward powers. Parameter FBR is calculated by subtracting the backward power from the forward power. The FBR values of the microstrip antenna arrays CMAA and PMAA are equal to 2.5 and $7.5 \mathrm{~dB}$ respectively. The FBR value of PMAA is greater than that of CMAA. This confirms that PMAA is a better antenna than CMAA in terms of FBR parameter. Tables II and III depict the comparison of measured results of CMAA and PMAA.

TABLE II. SUMMARIZED MEASURED RESULTS

\begin{tabular}{|c|c|c|c|c|c|}
\hline $\begin{array}{c}\text { Antenna } \\
\text { Type }\end{array}$ & $\begin{array}{c}\text { Resonant } \\
\text { Frequency } \\
(\mathbf{G H z})\end{array}$ & $\begin{array}{c}\text { Return } \\
\text { Loss (dB) }\end{array}$ & $\begin{array}{c}\text { Band } \\
\text { width } \\
\mathbf{( M H z )}\end{array}$ & $\begin{array}{c}\text { Band } \\
\text { width } \\
\mathbf{( \% )}\end{array}$ & $\begin{array}{c}\text { Gain } \\
(\mathbf{d B})\end{array}$ \\
\hline CMAA & 5.53 & -21.06 & 273 & 4.89 & 6.81 \\
\hline PMAA & 5.53 & -26.12 & 6050 & 109.45 & 20.33 \\
\hline
\end{tabular}

TABLE III. SUMMARIZED MEASURED RESULTS

\begin{tabular}{|l|l|l|l|l|}
\hline Antenna Type & FBR & $\mathbf{S}_{\mathbf{2 1}}(\mathbf{d B})$ & $\mathbf{S}_{\mathbf{3 1}}(\mathbf{d B})$ & $\mathbf{S}_{\mathbf{4 1}}(\mathbf{d B})$ \\
\hline CMAA & 2.5 & -16.95 & -14.22 & -17.30 \\
\hline PMAA & 7.5 & -31.44 & -36.41 & -31.62 \\
\hline
\end{tabular}

After comparing the performances of CMAA and PMAA, we can say that PMAA outperforms CMAA. It is producing enhanced bandwidth, higher gain, better reduction in mutual coupling and superior radiation characteristics compared to its counterpart.

\section{CONLUSIONS}

In this paper, a four element microstrip antenna array loaded with U-shape patch type EBG structure was 
investigated. Conventional and proposed microstrip antenna arrays were designed and fabricated successfully. The two dimensional EBG structure plays a prominent role in reducing the mutual coupling between the radiating patches below $-20 \mathrm{~dB}$ level. Furthermore, increase in gain by $13.52 \mathrm{~dB}$ is also obtained. The overall bandwidth (\%) of PMAA is increased to $109.45 \%$. Measured results of front and backward power confirm that the radiation properties of PMAA are enhanced compared to CMAA.

\section{REFERENCES}

[1] A. C. Balanis, Antenna Theory, Analysis and Design, John Wiley \& Sons, 1997

[2] I. J. Bahl, P. Bhartia, Microstrip Antennas, Artech House, 1980

[3] G. L. Matthaei, L. Young, E. M. T. Jones, Microwave Filters, Impedance-Matching Networks and Coupling Structures, Artech House Books, Massachusetts, 1980

[4] F. Yang, Y. Rahmat-Samii, Electromagnetic Band Gap Structures in Antenna Engineering, Cambridge University Press, 2009

[5] G. C. Christodoulou, F. P. Wahid, Fundamentals of Antennas: Concepts and Applications, Prentice Hall of India, 2004

[6] G. Kumar, K. P. Ray, Brodband Microstrip Antennas, Artech House Books, 1980

[7] D. N. Elsheakh, M. F. Iskander, E. A. Abdallah, H. A. Elsadek, H. Elhenawy, "Microstrip antenna array with new 2D-electromagnetic band gap structure shapes to reduce harmonics and mutual coupling", Progress in Electromagnetic Research C, Vol. 12, pp. 203-213, 2010

[8] F. Benikhelf, N. Boukli-Hacene, "Mutual coupling reduction in patch antenna arrays using EBG structure", International Journal of Computer Science Issues, Vol. 9, No. 4, pp.265-269, 2012

[9] M. M. Bait-Suwailam, F. O. Siddiqui, M. O. Ramahi, "Mutual coupling reduction between microstrip patch antennas using slottedcomplementary split-ring resonators", IEEE Antennas and Wireless Propagation Letters, Vol. 9, pp. 876-878, 2010

[10] D. Saxena, S. Agarwal, S. Srivastava, "Low cost E-shaped microstrip patch antenna array for WLAN", International Journal of Advanced Research in Electrical, Electronics and Instrumentation Engineering, Vol. 3, No. 4, pp. 8831-8838, 2014

[11] S. Shajahan, A. Vasuki, “A broadbanding microstrip patch antenna using electromagnetic band gap structures", International Journal of Pure and Applied Mathematics, Vol. 116, No. 11, pp. 71-79, 2017

[12] V. D. Katrodiya, N. J. Peshavaria, Vivek Ramamoorthy, "Design of microstrip patch antenna array for wireless appliations", International Journal of Electronics and Communication Technology, Vol. 6, No. 2, pp. 61-64, 2015

[13] Z. Illuz, R. Shavit, R. Bauer, "Microstrip antenna phased array with electromagnetic band gap substrate", IEEE Transactions on Antennas and Propogation, Vol. 52, No. 6, pp. 1446-1453, 2004

[14] N. Mittal, R. Khanna, J. Kaur, "Performance improvement of U-slot microstrip patch antenna for $\mathrm{rf}$ portable devices using electromagnetic band gap and defected ground structure", International Journal of Wireless and Microwave Technologies, Vol. 3, pp. 20-28, 2016

[15] R. Rana, N. Vyas, R. Verma, V. Kaushik, A. K. Arya, "Dual stacked wideband microstrip antenna array for Ku-Band applications", Vol. 4, No. 6, pp. 132-135, 2014

[16] A. Verma, "EBG structures and its recent advances in microwave antenna", International Journal of Scientific Research Engineering \& Technology, Vol. 1, No. 5, pp. 84-90, 2012 